\title{
Produção e estética dos conteúdos televisivos em ambiente de convergência: o caso da TV Unesp
}

\author{
Ana Silvia Lopes Davi Médola*
}

\section{Resumo}

Novos processos de produção de conteúdo estão reconfigurando os organogramas e os fluxogramas de setores ligados à criação de programas informativos e de entretenimento nas emissoras de televisão. A elaboração de conteúdos centrados em um modo de Comunicação que procura contemplar a participação e a colaboração da audiência nas construções discursivas impõe a existência de estruturas capazes de responder às demandas de uma plataforma multimídia, engendrada por tecnologias que possibilitem a conectividade entre os diversos dispositivos móveis e portáteis. Além de evidenciar os desafios de caráter organizacional, o presente trabalho, baseado em pesquisa bibliográfica e documental, tem como objetivo discutir as implicações estéticas dos conteúdos gerados para o consumo multimídia. Assim, toma como objeto de análise a estrutura e a programação da Televisão Universitária Unesp, da Universidade Estadual Paulista, em fase de implantação no campus de Bauru-SP.

Palavras chave: Televisão. Convergência. Produção Multimídia. Conectividade, Comunicação Colaborativa.

\section{Production and aesthetics of television contents in a converging environment: the TV Unesp case}

\section{Abstract}

New processes of content production are reconfiguring both organizational charts and flowcharts from sectors linked to the creation of informative and entertainment

\footnotetext{
* Professora doutora do Programa de Pós-Graduação em Comunicação (mestrado acadêmico) e da Pós-Graduação em TV Digital (mestrado profissional), Faculdade de Ciências Humanas, Artes, Arquitetura e Comunicação, Universidade Estadual Paulista - FAAC/UNESP, Bauru-SP, Brasil. Diretora da TV Unesp. Foi Coordenadora do Programa de Pós-Graduação em Comunicação da UNESP (2004-2007), vice-presidente da Compós - Associação Nacional dos Programas de Pós-Graduação em Comunicação (2007-2009) e vice-presidente da SOCICOM - Federação Brasileira da Associações Científicas e Acadêmicas de Comunicação (2008-2012).E-mail: anasilviamedola@gmail.com
} 
programs on television stations. The preparation of contents centered on a manner of communication which seeks to contemplate the participation and collaboration of the audience in discursive constructions imposes the existence of structures which are able to respond to the demands of a multimedia platform, engendered by technologies which enable connectivity among the several mobile and handheld devices. Besides highlighting the challenges of organizational character, this study, made with bibliographical and documentary researches, also aims to discuss the aesthetic implications of the contents generated for multimedia consumption. Therefore, it takes as object of analysis both structure and television programming from Televisão Universitária Unesp, at São Paulo State University, which is under implementation at Bauru campus.

Keywords: Television. Convergence. Multimedia Production. Connectivity. Collaborative Communication.

\section{Producción y estética de los contenidos televisivos en ambiente de convergência: lo caso de la TV Unesp \\ Resumen}

Nuevos procesos de producción de contenido están reconfigurando los organigramas y los diagramas de flujo de sectores vinculados a la creación de programas de entretenimiento en las estaciones de televisión. La elaboración de contenidos centrados en una forma de comunicación que busca contemplar la participación y la colaboración de la audiencia en las construcciones discursivas imponen la existencia de estructuras capaces de responder a las demandas de una plataforma multimedia, engendrada por tecnologías que posibilitan conectividad entre los diversos dispositivos móviles y portátiles. Además de resaltar los desafíos de carácter organizacional, el presente trabajo, con base e pesquisas bibliográfico y documental, pretende discutir las implicaciones estéticas de los contenidos generados para el consumo multimedia. Así, se toma como objeto de análisis la estructura y la programación de la Televisión Universitaria Unesp, de la Universidad Estadual Paulista, en fase de implantación en el campus de Bauru-SP. Palabras clave: Televisión. Convergencia. Producción Multimedia. Conectividad. Comunicación Colaborativa.

\section{Introdução}

E ste estudo tem como objeto de análise a estrutura e a programação da Televisão Universitária Unesp, da Universidade Estadual Paulista, em fase de implantação no campus de Bauru-SP. O objetivo é discutir as implicações estéticas dos conteúdos gerados para o consumo multimídia, além de evidenciar 
os desafios de caráter organizacional. Metodologicamente, se empregou a pesquisa bibliográfica e documental.

A implantação da TV Unesp, emissora da Universidade Estadual Paulista "Júlio de Mesquita Filho", com sede em Bauru, no Estado de São Paulo, está baseada em tecnologia digital e cria a oportunidade de estruturar uma televisão universitária sob novos parâmetros. Diferentemente das mídias tradicionais, voltadas às demandas da era industrial, a inexorável migração para as plataformas digitais está promovendo transformações em função do estabelecimento da Comunicação em rede, cuja lógica de uma estrutura mais horizontalizada, própria das interconexões, altera profundamente as relações entre sujeitos nos diversos níveis e fluxos de Comunicação. O sistema de televisão brasileiro está inserido nesse contexto de substituição das bases tecnológicas configurando uma realidade multifacetada, observável a partir de diferentes prismas e passível de abrigar posições e interesses absolutamente conflitantes por parte dos atores sociais envolvidos no processo.

Apesar de derivada dos avanços infoeletrônicos, a televisão denominada digital foi introduzida no Brasil a partir do aperfeiçoamento do padrão tecnológico japonês, colocando grandes desafios nos processos de apropriação sociocultural dessa nova televisão, com reflexos importantes nas estruturas econômicas e políticas que regem o sistema de televisão adotado no país. Vejamos: a televisão que conhecemos teve seus contornos delineados ao longo de seis décadas por meio de um tipo de legislação e conduta política que forjaram um modelo de televisão predominantemente comercial, estruturado em algumas poucas redes formadas por emissoras retransmissoras, sendo hegemônicas no quesito audiência, ainda que pesem os avanços de projetos promotores de diversificação da oferta de conteúdos, como a TV pública, por exemplo. Nesse modelo, as grandes redes comerciais cobrem a quase totalidade do território nacional em transmissão aberta e operam com uma produção verticalizada, isto é, realizam, senão integralmente, pelo menos a maior parte dos programas nacionais que exibem. Esta é a televisão que a imensa maioria dos brasileiros assiste.

Entretanto, observa-se na atualidade uma crise nas tendências que historicamente desenharam alguns dos modelos de televisão 
em países hegemônicos e periféricos: o impacto das tecnologias digitais os modelos de TV europeu, norte americano ou brasileiro. $\mathrm{Na}$ Europa, televisão é entendida como um serviço público desde o início das transmissões, enquanto o modelo adotado pelos norte-americanos não configura o serviço de televisão como sendo de caráter público, nem exclusivamente comercial, mas regido por forte regulamentação. Já o modelo brasileiro, assim como outros países periféricos, pode ser caracterizado como um sistema comercial no qual a propriedade privada, econômica e politicamente concentrada, mantém relações muito próximas com as instâncias governamentais.

Atentando para esse momento de transformação do sistema brasileiro de televisão que se estruturou comercialmente sob a lógica patrimonialista de operadores privados, favorecidos pela ausência de critérios de concessões de canais, acreditamos que uma televisão pública, que nasce em plataforma digital, tem a responsabilidade de apontar novos rumos contrapondo-se à lógica da televisão analógica que, no Brasil particularmente, foi muito bem sucedida para algumas empresas comerciais, representando um setor altamente concentrado e aberto à influência estrangeira na sua grade de programação. Neste contexto, experiências consideradas bem sucedidas no que diz respeito à televisão pública, comunitária, regional, são pontuais com oscilações importantes em suas trajetórias quando observadas na diacronia do percurso. Portanto, ao olhar para a trajetória do modelo de televisão brasileira instalado na segunda metade do século passado, fica evidente que em nosso país a forma de conceber e construir experiências de produção e consumo de TV favoreceu poucos grupos econômicos, concentrou poder político e não contribuiu para a promoção e preservação da diversidade cultural.

O projeto de implantação da TV Unesp tem a oportunidade de realizar um percurso diferente das experiências de emissoras universitárias criadas no sistema analógico que sempre enfrentaram muitas dificuldades para atender aos propósitos de emissoras de interesse público. Para além dos entraves decorrentes da produção limitada pela falta de recursos técnicos e financeiros, bem como pela morosidade da burocracia que permeia a administração pública, o fato de estarem inseridas em uma forma de conceber 
PRODUÇÃO E ESTÉTICA DOS CONTEÚDOS TELEVISIVOS EM AMBIENTE...

televisão pautada na audiência massiva impõe às TVs universitárias uma baixa inserção, embora reconhecidamente desempenhe papel relevante na diversificação da produção de conteúdos audiovisuais. Dotada de uma estrutura de equipamentos bastante sofisticada, com linha de produção totalmente digitalizada, a TV Unesp pode iniciar as atividades pautada em outras bases, a partir de uma estrutura atenta à contemporaneidade não apenas dos dispositivos técnicos, mas dos desdobramentos que a introdução desses dispositivos promovem na forma de produção, distribuição e consumo dos produtos midiáticos.

\section{Televisão e digitalização}

Desde os anos 1990 do século passado, o contexto televisivo brasileiro vem sendo lentamente alterado, notadamente pela introdução dos sistemas de transmissão por assinatura, pela maior presença das emissoras de interesse público, e também pela proliferação daquelas destinadas ao proselitismo religioso. Ainda que, com um volume de telespectadores relativamente modesto se comparado ao alcance das grandes redes da TV aberta, o fato é que a fragmentação da audiência promovida por novas formas de distribuição dos sinais antecipa aspectos do tipo de transformação que a digitalização dos sistemas intensifica, entre eles, a fragmentação da audiência.

O surgimento da TV digital implica também em uma série de desdobramentos decorrentes de um processo de mudança de plataforma tecnológica que altera radicalmente os modos de produzir e fazer circular conteúdos audiovisuais. Isso é muito relevante tendo em vista que o Brasil conta com um parque tecnológico e setores de produção e transmissão de TV operando em sistema analógico e que agora são instados a migrar para o sistema digital. O custo dessa migração vai muito além dos obstáculos inerentes à lógica da obtenção imediata do lucro, lógica essa que pode ser determinante caso não sejam formuladas políticas públicas claras sobre como o país irá absorver o impacto das redes telemáticas no sistema de radiodifusão. E nos movimentos que estão desenhando a implantação da digitalização da TV no Brasil, principalmente 
aqueles regidos pelos interesses do setor privado, é possível observar ações voltadas a preservar na nova plataforma aspectos essenciais do modelo de negócios da televisão analógica, o que pode vir a ser um grande equívoco para a própria sobrevivência das emissoras em operação.

Nesse período de transição é importante entender que as transformações colocadas em perspectiva na lógica convergente da digitalização dos meios podem alterar radicalmente a forma de apropriação sociocultural e econômica da televisão, de modo que certos hábitos sedimentados de consumo já não terão mais lugar no novo ambiente comunicacional. Tentar manter um modelo que vigorou no Brasil na segunda metade do século passado, e muito bem sucedido para alguns segmentos do setor produtivo, provavelmente redundará na impossibilidade de construir uma indústria audiovisual televisiva capaz de competir de forma equilibrada, em um futuro iminente, com grandes corporações que atuam nos mercados em escala mundial nos quais circulam e são comercializados bens culturais em suportes audiovisuais.

Em relação à linguagem, as condições técnicas da digitalização relativas ao desenvolvimento das possibilidades estéticas permeiam os debates em torno da imagem de alta definição e da interatividade em instâncias estratégicas da produção de conteúdos como a Publicidade, o Jornalismo, os programas esportivos e de entretenimento. Com isso, coloca-se a emergência de novos formatos na ecologia de transmediação descrita por Henry Jenkins (2008) e, potencialmente, de multiprogramação, abrindo perspectivas para a diversificação dos canais de circulação de conteúdos.

A necessidade de incorporar nos processos de Comunicação televisiva os conceitos advindos dos sistemas informatizados como a conectividade e a interatividade torna-se relevante no sentido de tentar promover a inserção das camadas excluídas da população nos novos fluxos comunicacionais, tentativa que depende primeiramente de políticas públicas que possam garantir a infraestrutura necessária para a universalização do acesso às tecnologias de informação e Comunicação. Sendo a televisão digital um dispositivo que permite Comunicação com base na interatividade, agregando a portabilidade e mobilidade, facilita o estabelecimento das relações 
PRODUÇÃO E ESTÉTICA DOS CONTEÚDOS TELEVISIVOS EM AMBIENTE...

colaborativas e da maior participação do telespectador. Reduzir a utilização dessas possibilidades aos interesses comerciais voltados ao entretenimento puro ou à informação unilateral é subestimar o potencial da Comunicação social nos ambientes multimidiáticos e desperdiçar uma grande chance de mudança.

\section{Da tela da TV para a TV nas telas}

Partindo do pressuposto de que televisão é antes de tudo "player" e que só pode desempenhar esse papel se houver conteúdo audiovisual a ser veiculado, estamos admitindo a possibilidade de separação entre produção e distribuição no fazer televisivo. Assim, o fato de televisão ser, em última instância, um sistema de transmissão de conteúdos audiovisuais significa que uma estrutura de televisão não precisa necessariamente ter uma estrutura de produção. Não obstante, seja por força de lei ou por estratégias de aproximação e identificação com o público, as emissoras brasileiras mantém sempre um mínimo de produção própria.

Também é premissa fundamental considerar que determinados produtos são característicos do meio televisivo como as transmissões diretas. Só a televisão pode transmitir som e imagem em movimento em tempo real. Enquanto característica televisiva mantém-se a organização de exibição de conteúdos pautada na noção de programação em fluxo (WILLIANS, 1975). Entretanto, mesmo se o conteúdo transmitido se caracterize como evento genuinamente televisivo, ou seja, algo passível de ser observado no momento mesmo em que ocorre por meio da transmissão de som e imagem em movimento em tempo real (FECHINE, 2008), ou se o telespectador não pode assistir no ato mesmo da transmissão, de qualquer forma, na convergência, esse conteúdo poderá ser acessado por demanda em outro momento ou em outro display. A mudança na forma de consumir introduzida pelas inovações tecnológicas gera alterações na forma de produzir.

Na plataforma digital a convergência transpõe o espectro de distribuição dos sinais eletromagnéticos. Os conteúdos ganham com a rede mundial de computadores uma nova via de circulação sendo acessados nos diferentes displays, ou seja, em telas de

Intercom - RBCC

São Paulo, v.35, n.2, p. 189-204, jul./dez. 2012

195 
computador, de telefones móveis, I Phones, I Pads, descentralizando geograficamente a recepção dos conteúdos. A recepção é, portanto, ampliada, de modo que a programação veiculada pela televisão digital terrestre e aberta do sistema brasileiro, poderá ser eventualmente veiculada na Internet. Certamente, os modelos de negócios serão determinantes na configuração dessas formas de distribuição, mas está claro que o modelo de transmissão de programas em fluxo para uma determinada área geográfica sofrerá alterações.

Considerar as questões relativas à produção própria e às formas de distribuição dos conteúdos das emissoras de televisão é relevante para estabelecer os objetivos e justificar a atuação de uma emissora de televisão de uma universidade como a Unesp, cuja característica multicampi evidencia uma peculiaridade geográfica que interfere sobremaneira no caráter institucional do propósito de implantar uma televisão universitária em uma das cidades onde está presente no Estado de São Paulo.

No tocante ao conteúdo, o qualificativo - universitária - traz implícito na concepção do projeto da emissora o fato de que o tipo de conteúdo a ser veiculado tangencia os aspectos relativos a uma instituição de ensino superior. Uma TV universitária carrega a ideia de que reflete em grande medida as atividades constitutivas do mundo da academia, da formação profissional, do desenvolvimento da pesquisa, da disseminação do conhecimento destinado à melhoria da qualidade de vida, enfim, de aspectos relativos à universidade enquanto instituição.

Em relação à circulação dos conteúdos, no contexto de convergência, sendo uma televisão meio de produção e plataforma de circulação, não pode ser pensada isoladamente. Isso porque, nesse início de século, não somente a televisão, mas todos os meios de Comunicação de massa que no século passado forjaram a sociedade midiática precisam ser encarados agora como elos integrantes de uma rede de Comunicação interconectada, dentro de uma visão ecológica da Comunicação (SCOLARI, 2009). No caso da TV Unesp, estabelecer a conexão intramuros possibilitando conhecer-se internamente, já que a dimensão de sua atuação nas diferentes áreas do conhecimento, assim como a presença em 23 cidades 
PRODUÇÃO E ESTÉTICA DOS CONTEÚDOS TELEVISIVOS EM AMBIENTE...

de diferentes regiões do Estado de São Paulo, muitas vezes não permitem à comunidade interna ter a percepção do seu alcance na totalidade. Para o público em geral, uma televisão universitária contribui para a divulgação científica, para a ampliação da capacidade de ensino e formação continuada com os cursos de educação a distância, a promoção da cidadania, da consciência política, ecológica, respeito à diversidade cultural, enfim, a possibilidade de contribuir para a disseminação de informação e conteúdos audiovisuais de qualidade.

Uma emissora universitária encontra no ecossistema midiático da contemporaneidade um ambiente rico de possibilidades no que diz respeito aos suportes para a difusão de informação e conhecimento. No entanto, a elaboração de conteúdos centrados em um modo de Comunicação que procura contemplar a participação e a colaboração da audiência nas construções discursivas impõe a existência de estruturas capazes de responder às demandas de uma plataforma multimídia, engendrada por tecnologias que possibilitam conectividade entre os diversos dispositivos móveis e portáteis. E essa interconexão entre redes telemáticas desencadeia práticas sociais de produção e consumo de conteúdos audiovisuais que estão alterando os organogramas e os fluxogramas de setores ligados à criação de programas nas emissoras de televisão.

De acordo com Castells (1999), a expansão nos sistemas de distribuição e acesso aos conteúdos promovidos por tecnologias como a dos satélites e a rede mundial de computadores, por exemplo, pode ser considerado fator de aceleração dos fluxos característicos da chamada "Revolução da Informação". A velocidade da circulação das informações impacta as estruturas e as relações de produção nos mais diversos segmentos da sociedade atual, à medida que exigem envolvimento, flexibilidade e inovação por parte dos atores envolvidos nos processos produtivos. Para atender a essas novas demandas, as organizações da era industrial terão que se capacitar culturalmente para a efetiva apropriação das tecnologias da informação.

Assim, os padrões de gestão que moldaram a produção e colocaram os produtos televisivos em circulação no padrão analógico devem agora ser revistos de modo a balizar o reposicionamento das 
organizações diante das constantes inovações relativas à TV, por exemplo. Sublinhamos o termo "constantes", pois, as inovações estão sempre em curso desencadeando muitas incertezas, como podemos observar no caso da adoção do padrão de TV digital no Brasil:

Com a escolha do padrão japonês, as inovações tecnológicas possíveis são a mobilidade, a interatividade e a multiprogramação, esta última já descartada pelas emissoras, inclusive com a proibição pelo governo. A interatividade ainda não é oferecida em larga escala e a mobilidade é uma aposta ainda para o futuro. Dessa forma, a TV digital, até o fim desse trabalho, não apresentou nenhuma inovação tecnológica expressiva, a não ser a alta definição das imagens e do som que somente é percebida por aqueles que possuem uma televisão compatível (MACHADO FILHO, 2011, p.149).

Em concordância com o autor, verificamos que no processo de implantação da TV digital a inovação mais facilmente identificável é a qualidade de som e imagem. Interatividade de fato depende da infra-estrutura de Banda Larga para a Internet, enquanto mobilidade só é possível nos locais onde há transmissão de sinais digitais. Enfim, concretamente, ainda há um caminho considerável a percorrer para que a infra-estrutura necessária esteja instalada. Mesmo assim, não há como não refletir sobre as alterações presentes nos programas de TV.

Discursivamente, o elemento novo mais perceptível diz respeito às estratégias para atrair a atenção do receptor no sentido de promover algum nível de interatividade, no sentido de motivar o telespectador a operar uma ação. Entretanto, no contexto de convergência, não bastará apenas criar discursivamente efeitos de sentido de interatividade, simulacros de participação com fins predominantemente mercadológicos. É preciso compreender e assimilar como a profunda transformação que a Comunicação em rede propiciada pela Internet altera a forma de Comunicação entre os indivíduos e a relação entre a Comunicação e o poder. A interatividade mediada pelo computador (PRIMO, 2007) é própria da Internet e somente a convergência dos meios poderá introduzir essa prática na TV. Mesmo assim, os reflexos na produção televisiva são facilmente identificáveis desde a composição estética das interfaces de interação, até a recorrente convocação do telespectador para 
PRODUÇÃO E ESTÉTICA DOS CONTEÚDOS TELEVISIVOS EM AMBIENTE...

participar por meio de outros dispositivos, notadamente o telefone e a Internet, reforçando uma conduta participativa.

Para dar a resposta que se imagina que o público quer, as estruturas organizacionais empresariais passam a repensar suas práticas, mas na academia, a Comunicação enquanto área de conhecimento, de investigação científica e formação profissional, o direcionamento da atenção para os problemas decorrentes da digitalização parece estar um pouco aquém no tocante à preparação de comunicadores para a nova realidade. Embora a questão da produção de conteúdo interativo seja atualmente uma das grandes preocupações de setores públicos e privados ligados à televisão, observam-se poucas mudanças, até o momento, nas estruturas curriculares voltadas a refletir as implicações e desafios que se apresentam à produção de conteúdos para TV digital. Talvez isso possa ser explicado pelo fato de que na vanguarda dos processos decisórios estiveram presentes representantes dos setores responsáveis pelo desenvolvimento das bases tecnológicas que culminaram com o ISDTV - International System for Digital TV - além dos conglomerados empresariais interessados em preservar seu status quo. Talvez isso explique em parte o pouco envolvimento acadêmico em torno da discussão sobre o desenvolvimento de conteúdos para a TV digital, o que cria um abismo entre o tipo de formação dada pela universidade e as reais demandas que o profissional encontra no mercado.

Importante ressaltar que não basta projetar perspectivas de produção com base apenas no potencial tecnológico, ou a partir das experiências de televisão digital realizadas em outros países. A Comunicação televisiva é socioletal, ou seja, deve ser considerada a partir das relações estabelecidas em diferentes bases socioculturais. Nesse sentido, a formação acadêmica deve considerar o fato de a televisão ser um meio com inserção social conotativa e, por isso, os conteúdos resultantes da televisão digital terão características derivadas também da tecnologia, mas conforme a relação estabelecida entre os pólos da Comunicação. Nesse sentido, com a implantação da TV Unesp, os egressos dos Cursos de Comunicação Social em nível de graduação e pós-graduação mantidos pela instituição, têm a possibilidade de obter formação 
de caráter estratégico do ponto de vista sociocultural e econômico em função do tipo de contribuição do novo dispositivo televisivo para o fortalecimento e desenvolvimento da produção audiovisual brasileira. A TV Unesp será o lugar de formação e de desenvolvimento de pesquisa para atender às demandas sociais da produção de conteúdos audiovisuais.

\section{O projeto TV Unesp}

O início das transmissões da TV Unesp em 04 de novembro de 2011 inaugura uma proposta de TV universitária que passou por uma revisão conceitual a partir de setembro de 2010 visando implantar um modelo de televisão universitária digital inserida em um ambiente de convergência midiática. Isso coloca desafios de caráter organizacional até então não existentes, por exemplo, a necessidade de pensar a produção de conteúdos televisivos com interfaces para outras plataformas. Não se trata da reprodução dos programas em outros meios, mas sim o desdobramento dos conteúdos informativos e de entretenimento de forma articulada com outros sistemas tecnológicos de transmissão e, consequentemente, outras linguagens.

A base organizacional de uma emissora analógica está dividida em setores responsáveis pela infra-estrutura de engenharia de captação e transmissão de sinais, com setores de operação e manutenção. Na produção de conteúdo, o departamento de Jornalismo e, em uma emissora pequena, sem projetos de desenvolvimento de dramaturgia, um departamento denominado "produção" encarregado dos programas não jornalísticos. Como apoio a ambos os setores está o setor de videografismo. Resumidamente essa foi a estrutura básica pensada inicialmente também para a TV Unesp.

Com a revisão do projeto apontando para as demandas do contexto de convergência, para além de elaborar os telejornais diários e programas de entrevistas e debates, gêneros clássicos do Jornalismo em televisão, o departamento de Jornalismo da emissora passou a estruturar-se de modo a trabalhar com a produção colaborativa agregando material proveniente de outras instituições universitárias e desenvolvendo parcerias em coproduções. A equipe 
PRODUÇÃO E ESTÉTICA DOS CONTEÚDOS TELEVISIVOS EM AMBIENTE...

está aberta à incorporação dos conteúdos gerados pelas redes sociais em seus noticiários e pela participação direta do público com a veiculação de "reportagens" e/ou imagens enviadas pelo público para a redação, conforme já ocorre em diversas experiências do chamado Jornalismo open source de caráter colaborativo (BRAMBILLA, 2005). Também o setor de produção passou a incorporar já na concepção dos programas as estruturas colaborativas, como no musical "Som e Prosa", no qual o público acessa ainda pela Internet os vídeos do artista da semana, monta sua play list, grava vídeos e posta registros de sua banda.

Para atender a essa demanda foi criado um departamento de multimídia capaz de processar e distribuir de forma articulada a produção televisiva bem como seu excedente de conteúdo para outros meios. A Internet com suas redes sociais, blogs, sites, chats, constituem o ambiente de reverberação dos conteúdos veiculados na televisão. Dessa forma, o departamento de multimídia é uma estrutura que se impõe pela necessidade de disponibilizar os conteúdos televisivos também em outras plataformas de modo a dar visibilidade ampliada à experiência de uma televisão universitária em base convergente, bem como intensificar a integração com o público.

O setor multimídia atua em paralelo com os demais setores ligados à produção de conteúdos como o Jornalismo, produção e videografismo. No organograma de funcionamento não há ascendência de um setor sobre o outro, configurando uma estrutura flexível, baseada na ação colaborativa de trocas de experiências e conhecimentos em busca de soluções inovadoras para os formatos próprios da TV digital.

Visando integrar a TV Unesp em diferentes dispositivos de circulação de conteúdos, o setor multimídia atua no desenvolvimento de sete áreas simultaneamente que vai do desenvolvimento do site à captação de conteúdos e participação do público. $\mathrm{O}$ desenvolvimento em web, por exemplo, objetiva reunir todas as informações e programas produzidos pela TV Unesp em espaço integrado criando um portal na Internet com todas as ações multimídia da emissora. Dessa forma, será possível oferecer a programação ao vivo e por demanda na Internet, visando garantir assim o acesso à programação por parte das demais unidades universitárias da

Intercom - RBCC

São Paulo, v.35, n.2, p. 189-204, jul./dez. 2012

201 
Unesp, presentes nas outras cidades do estado. O portal significa divulgar e apoiar os projetos de Educação a Distância em desenvolvimento na instituição, atuando como centro de armazenamento e recuperação de dados audiovisuais on demand.

A participação do público será privilegiada pela captação de conteúdos e pelo gerenciamento de redes sociais, entendendo que estas significam uma ação efetiva de interação, muito diferente da interatividade programada e reativa experimentada até o momento por TVs digitais em países como a Inglaterra. As redes sociais adquiriram importante papel na relação de Comunicação das instituições com seu público e podem ser entendidas como ambiente dialógico e polifônico dos processos comunicativos contemporâneos.

Todas as iniciativas elencadas são experiências já realizadas em televisões e empresas de Comunicação no Brasil e em países mais avançados, ainda que em escala bastante reduzida. $\mathrm{O}$ objetivo é criar as condições para a verificação das possibilidades de desenvolvimento novas formas expressivas, abrindo espaço para a experimentação e desenvolvimento de sistemas de Comunicação voltados ao interesse público. Nesse caso, a TV Unesp, enquanto emissora de uma instituição de ensino e pesquisa, se coloca como lugar de investigação e experimentação nas áreas de Comunicação, ciências da computação e ciências da informação com foco no aprimoramento científico capaz de apontar caminhos para a Comunicação na sociedade da informação.

\section{Conclusão}

Considerando, portanto, o fato de a Universidade Estadual Paulista (UNESP) ser uma instituição pública que mantém de forma integrada no campus de Bauru a TV Unesp, o Departamento de Comunicação Social e o Programa de Pós-Graduação em TV Digital, vimos que a pesquisa em televisão desenvolvida no âmbito dessas estruturas pode oferecer relevante contribuição para a compreensão sobre os impactos e das novas perspectivas em relação aos processos de Comunicação televisiva a partir da incorporação dos sistemas informatizados. Para além do papel natural de divulgação de conteúdos educativos, culturais e institucionais, 
no âmbito da extensão, no contexto em que está inserida, a TV Unesp, enquanto Televisão Universitária, constitui uma estrutura norteada pela investigação científica e, portanto, incorporada como um laboratório privilegiado capaz de atender a diferentes demandas colocadas pelas transformações profundas pelas quais passa o sistema de televisão brasileiro.

Procuramos demonstrar a contribuição do projeto da TV Unesp no sentido de atuar na realização de estudos de tendências em torno da estética dos conteúdos televisuais, assim como projeções de alguns cenários sobre formas de consumo em contexto de convergência. Ao apontar para a distribuição multiplataforma, em sistemas de TV broadcasting/broadband, acessadas por dispositivos móveis, portáteis, os chamados dispositivos de segunda tela, novos valores são colocados na arena midiática da circulação dos conteúdos, para os quais a academia, locus da TV Unesp, tem o compromisso de estar atenta.

\section{Referências}

BRAMBILLA, Ana Maria. Jornalismo open source em busca de credibilidade. In: Congresso Brasileiro Interdisciplinar de Ciências da Comunicação (Intercom), 09, Rio de Janeiro, 2005. Anais... Disponível em: http://www6.ufrgs.br/ limc/PDFs/Ana_4.pdf. Acesso em: 15 out. 2010.

CASTELLS, Manuel. Comunicación y poder. Traducción María Hernandez. Madrid: Alianza Editorial, 2009.

. A era da informação: economia, sociedade e cultura. V. 3. São Paulo: Paz e Terra, 1999.

FECHINE, Yvana. Televisão e presença: uma abordagem semiótica da transmissão direta. São Paulo: Estação das Letras e Cores, 2008.

JENKINS, Henry. Cultura da convergência. Tradução Susana Alexandria. São Paulo: Aleph, 2008.

MACHADO FILHO, Francisco. TV digital aberta no Brasil: desafios e tendências. Tese de Doutorado. São Bernardo do Campo: Universidade Metodista de São Paulo, 2011. 
PRIMO, Alex. Interação mediada por computador: Comunicação, cibercultura, cognição. Porto Alegre: Sulina, 2007.

SCOLARI, Carlos Alberto. Ecología de la hipertelevisión. Complejidad narrativa, simulación y transmedialidad en la televisión contemporânea. In: SQUIRRA, S.; FECHINE, Y. (Orgs.). Televisão digital: desafios para a comunicação. Porto Alegre: Sulina, 2009.

WILLIAMS, Raymond. Television: technology and cultural form. Nova York: Schoken Books, 1975.

Recebido: 30.05.201

Aceito: 15: 09.2012 